Article

\title{
Redox-Modulations of Photophysical and Single-molecule Magnet Properties in Ytterbium Complexes Involving Extended-TTF Triads
}

\author{
Bertrand Lefeuvre ${ }^{1}$, Jessica Flores Gonzalez ${ }^{1}$, Frédéric Gendron ${ }^{1}$, Vincent Dorcet ${ }^{1}$, \\ François Riobé ${ }^{2} \mathbb{D}$, Vladimir Cherkasov ${ }^{3}{ }^{\mathbb{D}}$, Olivier Maury ${ }^{2}$, Boris Le Guennic ${ }^{1}{ }^{\mathbb{D}}$, \\ Olivier Cador ${ }^{1}$, Viacheslav Kuropatov ${ }^{3, *(\mathbb{D})}$ and Fabrice Pointillart 1,*(D) \\ 1 Univ Rennes, CNRS, ISCR (Institut des Sciences Chimiques de Rennes)—UMR 6226, 35000 Rennes, France; \\ bertrand.lefeuvre@univ-rennes1.fr (B.L.); jessica.flores-gonzales@univ-rennes1.fr (J.F.G.); \\ frederic.gendron@univ-rennes1.fr (F.G.); vincent.dorcet@univ-rennes1.fr (V.D.); \\ boris.leguennic@univ-rennes1.fr (B.L.G.); olivier.cador@univ-rennes1.fr (O.C.) \\ 2 Univ Lyon, Ens de Lyon, CNRS UMR 5182, Université Claude Bernard Lyon 1, Laboratoire de Chimie, \\ F69342 Lyon, France; francois.riobe@ens-lyon.fr (F.R.); olivier.maury@ens-lyon.fr (O.M.) \\ 3 G. A. Razuvaev Institute of Organometallic Chemistry of Russian Academy of Sciences, GSP-445, \\ Tropinina str. 49, 603950 Nizhny Novgorod, Russia; cherkasov@iomc.ras.ru \\ * Correspondence: viach@iomc.ras.ru (V.K.); fabrice.pointillart@univ-rennes1.fr (F.P.); \\ Tel.: +79-(0)51902995 (V.K.); Tel.: +33-(0)223236752 (F.P.)
}

Academic Editors: Dawid Pinkowicz and Robert Podgajny

Received: 20 December 2019; Accepted: 22 January 2020; Published: 23 January 2020

\begin{abstract}
The reaction between the 2,2'-benzene-1,4-diylbis(6-hydroxy-4,7-di-tert-butyl-1,3-benzodithiol2-ylium-5-olate triad $\left(\mathrm{H}_{2} \mathrm{SQ}\right)$ and the metallo-precursor $\left[\mathrm{Yb}(\mathrm{hfac})_{3}\right] \cdot 2 \mathrm{H}_{2} \mathrm{O}$ led to the formation of a dinuclear coordination complex of formula $\left[\mathrm{Yb}_{2}(\mathrm{hfac})_{6}\left(\mathrm{H}_{2} \mathrm{SQ}\right)\right] \cdot 0.5 \mathrm{CH}_{2} \mathrm{Cl}_{2}\left(\mathrm{H}_{2} \mathrm{SQ}-\mathrm{Yb}\right)$. After chemical oxidation of $\mathbf{H}_{2} \mathbf{S Q}$ in 2,2'-cyclohexa-2,5-diene-1,4-diylidenebis(4,7-di-tert-butyl-1,3-benzodithiole- 5,6-dione (Q), the latter triad reacted with the $\left[\mathrm{Yb}(\mathrm{hfac})_{3}\right] \cdot 2 \mathrm{H}_{2} \mathrm{O}$ precursor to give the dinuclear complex of formula $\left[\mathrm{Yb}_{2}(\mathrm{hfac})_{6}(\mathbf{Q})\right](\mathbf{Q}-\mathbf{Y b})$. Both dinuclear compounds have been characterized by $\mathrm{X}$-ray diffraction, DFT optimized structure and electronic absorption spectra. They behaved as field-induced Single-Molecule Magnets (SMMs) nevertheless the chemical oxidation of the semiquinone to quinone moieties accelerated by a factor of five the relaxation time of the magnetization of $\mathbf{Q}-\mathbf{Y b}$ compared to the one for $\mathbf{H}_{2} \mathbf{S Q}-\mathbf{Y b}$. The $\mathbf{H}_{2} \mathbf{S Q}$ triad efficiently sensitized the $\mathrm{Yb}{ }^{\mathrm{III}}$ luminescence while the chemical oxidation of $\mathbf{H}_{\mathbf{2}} \mathbf{S Q}$ into $\mathbf{Q}$ induced strong modification of the absorption properties and thus a quenching of the $\mathrm{Yb}$ III luminescence for $\mathbf{Q}-\mathbf{Y b}$. In other words, both magnetic modulation and luminescence quenching are reached by the oxidation of the protonated semiquinone into quinone.
\end{abstract}

Keywords: ytterbium; extended-tetrathiafulvalene; electro-activity; single-molecule magnet; luminescence

\section{Introduction}

Molecular magnetism is in intense expansion since the discovery of the first Single-Molecule Magnet (SMM) behavior for a $\mathrm{Mn}_{12}$ cluster [1] and a decade later the similar magnetic behavior for a mononuclear lanthanide complex [2]. The motivation for this kind of nanomagnets comes from the potential applications in high density data storage $[3,4]$ especially since the development of organometallic chemistry allowing the discovery of "high blocking temperature" SMM [5-8]. The magnetic properties of the lanthanide ions strongly depend on the crystal field and slight variations of the electronic distribution of the lanthanides' surrounding, making such ions excellent candidates for magnetic switches [9-18]. Among the possible magnetic property switches, those playing with oxidation-reduction reactions are the most promising because such a stimulus can lead to drastic 
modifications in the electronic properties of the molecular system. Oxidation-reduction reactions can be achieved thanks to redox-active metal centers [19-21] or/and organic ligands [22-24]. Lanthanides are also well-known for their luminescence ranging from the visible to the near infrared (NIR) region $[25,26]$. The sensitization of their emission is achieved by antenna effect involving singlet $[27,28]$ and triplet [29-31] states of a (metallo)organic chromophore which can be energetically changed by oxido-reduction reaction leading to redox commutation of the NIR luminescence [32-35].

In this article, we proposed to exploit the ligand 2,2'-benzene-1,4-diylbis(6-hydroxy-4,7-di-tert-butyl1,3-benzodithiol-2-ylium-5-olate [36] $\left(\mathbf{H}_{\mathbf{2}} \mathbf{S Q}\right.$ ) (Scheme 1), which is suitable for lanthanide coordination, [37] and its oxidized form 2,2'-cyclohexa-2,5-diene-1,4-diylidenebis(4,7-di-tert-butyl-1,3-benzodithiole-5,6dione $(\mathbf{Q})$ (Scheme 1) to modulate both photophysical and magnetic properties of their corresponding complexes $\left[\mathrm{Yb}_{2}(\mathrm{hfac})_{6}\left(\mathbf{H}_{2} \mathbf{S Q}\right)\right] \cdot 0.5 \mathrm{CH}_{2} \mathrm{Cl}_{2}\left(\mathbf{H}_{\mathbf{2}} \mathbf{S Q} \mathbf{Q} \mathbf{Y b}\right)$ and $\left[\mathrm{Yb}_{2}(\mathrm{hfac})_{6}(\mathbf{Q})\right](\mathbf{Q}-\mathbf{Y b})\left(\mathrm{hfac}^{-}=1,1,1,5,5,5-\right.$ hexafluororacetylacetonate).<smiles>CC(C)(C)C1=C(O)C(C(C)(C)C)=c2sc(=c3ccc(=C4Sc5c(c(C(C)(C)C)c(Cl)c(O)c5C(C)(C)C)S4)cc3)c(C(C)(C)C)c2S1</smiles>

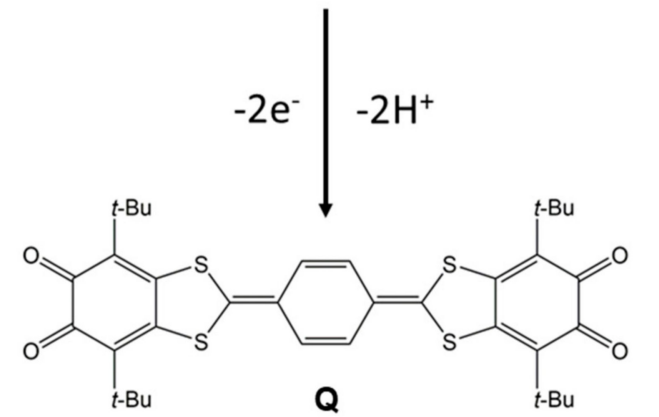

Scheme 1. Molecular structures of the $\mathbf{H}_{2} \mathbf{S Q}$ and $\mathbf{Q}$ ligands and intramolecular electron transfer in $\mathrm{H}_{2} \mathrm{SQ}$.

\section{Results and Discussion}

\subsection{X-Ray Structures}

The coordination reaction of the 2,2'-benzene-1,4-diylbis(6-hydroxy-4,7-di-tert-butyl-1,3-benzodithiol2-ylium-5-olate triad $\left(\mathbf{H}_{2} \mathbf{S Q}\right)$ (Scheme 1) and tris(1,1,1,5,5,5-hexafluoro-acetylacetonate)bis (aqueous) $\mathrm{Yb}^{\mathrm{III}}$ $\left(\mathrm{Yb}(\mathrm{hfac})_{3} \cdot 2 \mathrm{H}_{2} \mathrm{O}\right)$ in $\mathrm{CH}_{2} \mathrm{Cl}_{2}$ led to the formation of the dinuclear complex of formula $\left[\mathrm{Yb}_{2}(\mathrm{hfac})_{6}\left(\mathbf{H}_{2} \mathrm{SQ}\right)\right]$ $\cdot 0.5 \mathrm{CH}_{2} \mathrm{Cl}_{2}\left(\mathbf{H}_{2} \mathbf{S Q} \mathbf{Y b}\right)$. The oxidized form of $\mathbf{H}_{2} \mathrm{SQ}$ was obtained using an excess of $\mathrm{MnO}_{2}$, the resulting $\mathrm{Q}$ ligand (Scheme 1) was immediately reacted with $\mathrm{Yb}(\mathrm{hfac})_{3} \cdot 2 \mathrm{H}_{2} \mathrm{O}$ leading to the dinuclear complex $\left[\mathrm{Yb}_{2}(\mathrm{hfac})_{6}(\mathbf{Q})\right](\mathbf{Q}-\mathbf{Y b})$.

\subsection{1. $\left[\mathrm{Yb}_{2}(\mathrm{hfac})_{6}\left(\mathrm{H}_{2} \mathrm{SQ}\right)\right] \cdot 0.5 \mathrm{CH}_{2} \mathrm{Cl}_{2}\left(\mathrm{H}_{2} \mathrm{SQ}-\mathrm{Yb}\right)$}

$\mathbf{H}_{2} \mathbf{S Q}-\mathbf{Y b}$ crystallizes in the monoclinic space group $\mathrm{P} 2_{1} / \mathrm{c}$ (No. 14) (Figure 1 and Figure S1, Table S1). The asymmetric unit is composed by one molecule of $\left[\mathrm{Yb}_{2}(\mathrm{hfac})_{6}\left(\mathbf{H}_{2} \mathrm{SQ}\right)\right]$ and one half dichloromethane molecule of crystallization. The $\mathrm{Yb}(\mathrm{hfac})_{3}$ units are linked to the two terminal monoprotonated semiquinone coordination sites. A bischelating coordination mode is observed through both $\mathrm{C}_{-} \mathrm{O}^{-}$and $\mathrm{C}-\mathrm{OH}$ groups (Figure 1). The coordination strength with the $\mathrm{C}_{-} \mathrm{O}^{-}$is stronger than the one with $\mathrm{C}-\mathrm{OH}$ as attested by the $\mathrm{Yb}-\mathrm{OH}$ distances (2.408(5) $\AA$ ) which are much longer than the $\mathrm{Yb}-\mathrm{O}^{-}$distances $(2.178(4) \AA)$. The limit case in which the coordination reaction takes place

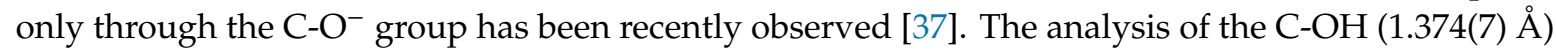


and $\mathrm{C}^{-} \mathrm{O}^{-}(1.295(7) \AA)$ bond lengths agrees with the protonated form of the semiquinone moieties. In order to confirm the oxidation state of the triad, the bond lengths of the ligand are carefully analyzed since an intramolecular electron transfer can take place from $\mathbf{H}_{\mathbf{2}} \mathbf{S Q}$ to $\mathbf{H}_{\mathbf{2}} \mathbf{S Q a}$ (Scheme 1). The 1,3-dithiole rings in $\mathbf{H}_{2} \mathbf{S Q} \mathbf{S} \mathbf{Y b}$ is essentially aromatic since the S1-C15 (1.692(6) $\AA$ ), S2-C15 (1.660(6)

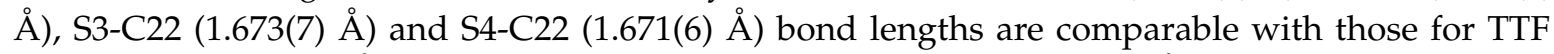

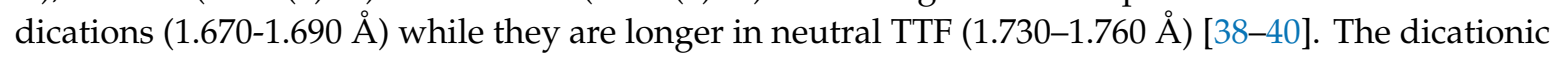
character of the extended TTF induced a single character of the C15-C16 and C21-C22 bonds as observed with the distances of 1.445(8) $\AA$ and 1.458(8) $\AA$. The bond lengths distribution in the terminal six-membered rings in bridging ligand in $\mathbf{H}_{2} \mathbf{S Q} \mathbf{Y} \mathbf{Y b}$ is also different from typical o-quinone distribution. The shortest distances in these rings were observed for bonds connecting $t$-Bu-substituted and carbonyl carbon atoms.

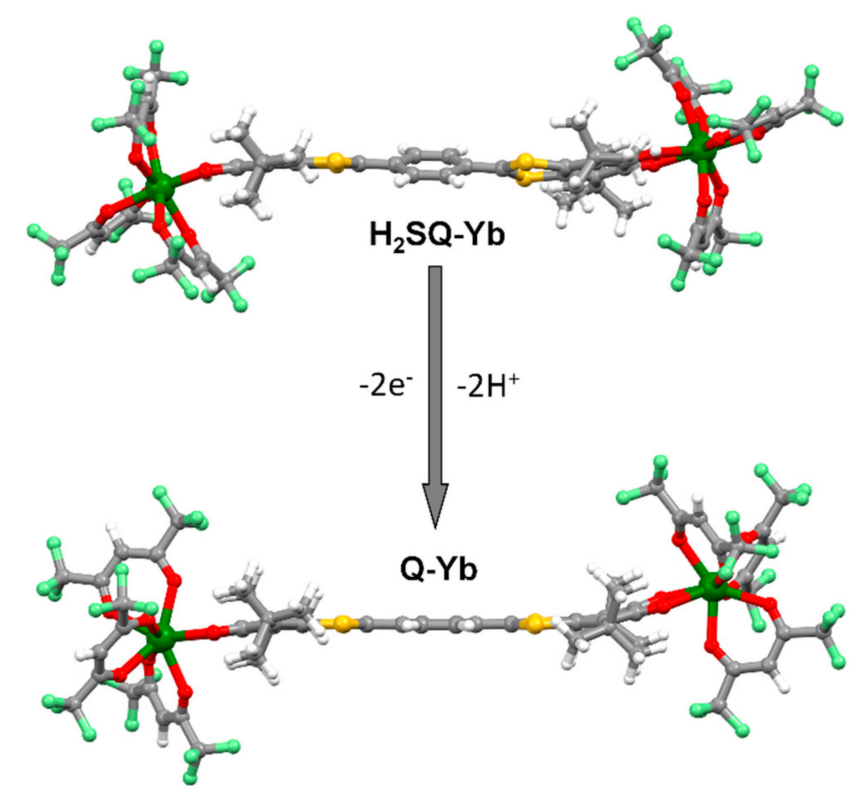

Figure 1. Experimental molecular structure of $\mathbf{H}_{2} \mathbf{S Q}-\mathbf{Y b}$ and DFT optimized structure of its oxidized form $\mathbf{Q}-\mathbf{Y b}$. Molecules of crystallization are omitted for clarity.

Finally, the protonated semiquinone form of the triad with charge-separated structure is also confirmed by the non-planarity of the ligand since the central $p$-phenylene ring and the two 6-hydroxy-4,7-di-tert-butyl-1,3-benzodithiol moieties formed a torsion angle of 26.2(2) ${ }^{\circ}$ in agreement with the one found in the X-ray structure of the free $\mathbf{H}_{2} \mathbf{S Q}$ ligand [36]. Thus each $\mathrm{Yb}^{\mathrm{III}}$ ion is surrounded by eight oxygen atoms coming from the three hfac anions and the bischelating $\mathrm{H}_{2} \mathrm{SQ}$ ligand. The coordination sphere around the metal center can be described as distorted triangular dodecahedron ( $\mathrm{D}_{2 \mathrm{~d}}$ symmetry) (SHAPE analysis, Table S2) [41].

The crystal packing reveals a good isolation of the two inorganic and organic sub-networks since nor $\pi-\pi$ interaction either S...S contact are identified (Figure 2) which is quite unusual for this kind of $\pi$-extended sulfured systems. The integrity of the crystal is assumed by $\mathrm{H} \cdots \mathrm{F}$ interactions. The $\mathrm{Yb}-\mathrm{Yb}$ intramolecular distance is $21.477 \AA$ while the shortest $\mathrm{Yb}-\mathrm{Yb}$ intermolecular distance is $10.000 \AA$. 


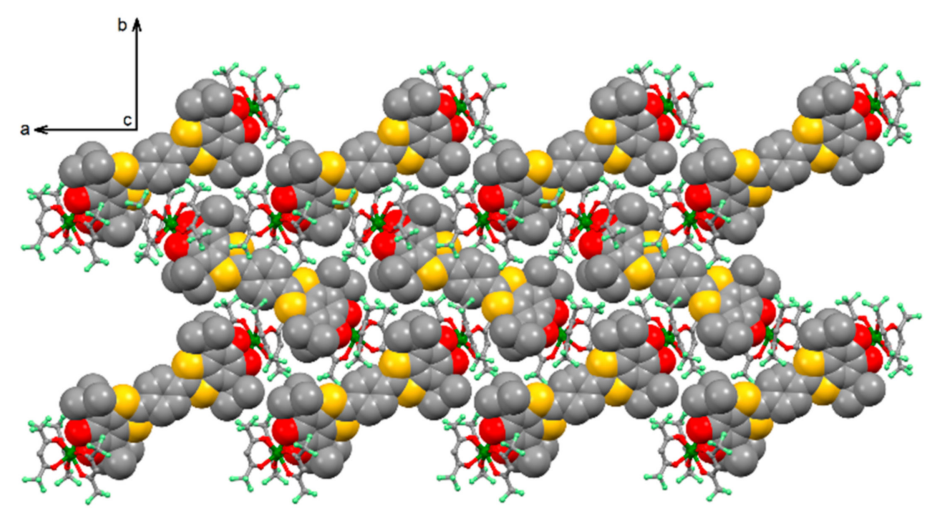

Figure 2. Crystal packing of $\mathbf{H}_{\mathbf{2}} \mathbf{S Q} \mathbf{Y} \mathbf{Y b}$ in the (110) plane. "Spacefill" and "ball and sticks" representations are used for $\mathbf{H}_{2} \mathrm{SQ}$ ligands and $\mathrm{Yb}(\mathrm{hfac})_{3}$ units, respectively.

\subsection{2. $\left[\mathrm{Yb}_{2}(\mathrm{hfac})_{6}(\mathrm{Q})\right](\mathrm{Q}-\mathrm{Yb})$}

Despite all the attempts to obtain suitable single crystals of $\mathbf{Q}-\mathbf{Y b}$ for diffraction studies, we did not succeed. Consequently based on the $\mathrm{X}$-ray structure of a previous system associated $\mathrm{Yb}(\mathrm{hfac})_{3}$ unit and quinone-based tetrathiafulvalene ligand [42], the structure of $\mathbf{H}_{\mathbf{2}} \mathbf{S Q} \mathbf{Q} \mathbf{L u}$ and Q-Lu (Figure 1) have been optimized with the help of DFT (see Experimental Section for computational details and Table S4). The X-ray structure of $\mathbf{H}_{\mathbf{2}} \mathbf{S Q} \mathbf{Q} \mathbf{Y b}$ is well reproduced by the DFT calculations despite the replacement of the $\mathrm{Yb}$ (III) ions by diamagnetic $\mathrm{Lu}(\mathrm{III})$ ions. Only a minor lengthening of the metal-ligand bond lengths is calculated in $\mathbf{H}_{\mathbf{2}} \mathbf{S Q}$ - $\mathbf{L u}$ when compared to $\mathbf{H}_{\mathbf{2}} \mathbf{S Q} \mathbf{Y} \mathbf{Y b}$ (see Table S4). In Q-Lu, the two quinone moieties act as bischelating coordination site. The average six Lu- $\mathrm{O}_{\mathrm{hfac}}$ distances $(2.319 \AA)$ are shorter than the average two $\mathrm{Lu}-\mathrm{O}_{\text {quinone }}$ ones $(2.360 \AA)$ leading to distorted square antiprism $\left(\mathrm{D}_{4 \mathrm{~d}}\right)$ coordination environment around the $\mathrm{Lu} \mathrm{u}^{\mathrm{III}}$ ions (SHAPE analysis, Table S2). The quinone form is confirmed by i) the $\mathrm{C}=\mathrm{O}$ bond length of $1.267 \AA$ shorter than the $\mathrm{C}-\mathrm{OH}$ and $\mathrm{C}^{-} \mathrm{O}^{-}$observed for the protonated semiquinone form and in agreement with the quinone form previously observed for quinone-based TTF and ii) with the almost planar shape of the $\mathbf{Q}$ ligand (torsion angle of $3.7^{\circ}$ ) because of the increasing of the aromaticity character of the ligand after oxidation. The coordination of the $\mathrm{Yb}(\mathrm{hfac})_{3}$ units plays a crucial role in the stabilization of the $\mathbf{Q}$ ligand since it was previously established that such an oxidized form of the free ligand cannot be isolated in solid-state due to its instability [36]. The Lu-Lu intramolecular distance is $21.664 \AA$.

\subsection{Magnetic Properties}

\subsubsection{Static Magnetic Measurements}

The temperature dependence of $\chi_{M} T$ for the samples $\mathbf{H}_{\mathbf{2}} \mathbf{S Q} \mathbf{Q} \mathbf{Y b}$ and $\mathbf{Q}-\mathbf{Y b}$ are given for two $\mathrm{Yb}^{\mathrm{III}}$ centers and represented in Figure 3. The room temperature values are $4.30 \mathrm{~cm}^{3} \cdot \mathrm{K}^{\prime} \cdot \mathrm{mol}^{-1}$ and $5.08 \mathrm{~cm}^{3} \mathrm{~K} \mathrm{~mol}^{-1}$ for $\mathbf{H}_{2} \mathbf{S Q} \mathbf{Y} \mathbf{b}$ and $\mathbf{Q}-\mathbf{Y b}$, respectively.

Such values are in the range of observed values for $\mathrm{Yb}^{\mathrm{III}}$-based molecular systems [43] and in agreement with the expected value for two $\mathrm{Yb}{ }^{I I I}$ ions $\left(5.14 \mathrm{~cm}^{3} \mathrm{~K} \mathrm{~mol}^{-1},{ }^{2} \mathrm{~F}_{7 / 2}\right.$ ground state multiplet) [44]. Upon cooling, $\chi_{M} T$ decreases monotonically down to $2.24 \mathrm{~cm}^{3} \cdot \mathrm{K} \cdot \mathrm{mol}^{-1}$ and $2.19 \mathrm{~cm}^{3} \mathrm{~K} \mathrm{~mol}^{-1}$ at $2 \mathrm{~K}$ for $\mathbf{H}_{\mathbf{2}} \mathbf{S Q} \mathbf{Y} \mathbf{Y b}$ and $\mathbf{Q}-\mathbf{Y b}$, respectively. Taking into account the intra- and intermolecular distance between the metal centers, the decrease of the $\chi_{M} T$ products is attributed to the thermal depopulation of the $\mathrm{M}_{\mathrm{J}}$ states. $\mathbf{H}_{\mathbf{2}} \mathbf{S Q} \mathbf{Q} \mathbf{Y b}$ and $\mathbf{Q}-\mathbf{Y b}$ exhibited similar magnetization with experimental values of $3.26 \mathrm{~N} \beta$ and $3.34 \mathrm{~N} \beta$ at $50 \mathrm{kOe}$, respectively [44]. 


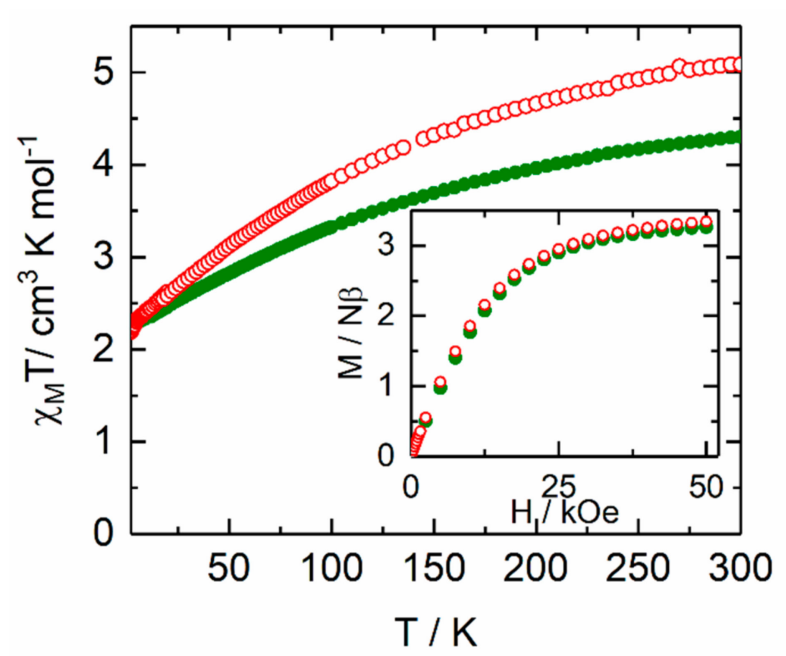

Figure 3. Temperature dependences of $\chi_{M} \mathrm{~T}$ for $\mathbf{H}_{\mathbf{2}} \mathbf{S Q} \mathbf{Q} \mathbf{Y b}$ (green) and $\mathbf{Q}-\mathbf{Y b}$ (red) in applied magnetic field of $10 \mathrm{kOe}$ between 20 and $300 \mathrm{~K}$ while a magnetic field of only $2 \mathrm{kOe}$ was used between 2 and $20 \mathrm{~K}$. In inset, the field variations of the magnetization at $2 \mathrm{~K}$ for $\mathbf{H}_{\mathbf{2}} \mathbf{S Q} \mathbf{Q} \mathbf{Y b}$ (green) and $\mathbf{Q}-\mathbf{Y b}$ (red) between 0 and $50 \mathrm{kOe}$.

\subsubsection{Dynamic Magnetic Measurements}

The in-phase and out-of-phase components of the ac susceptibility $\left(\chi_{M}{ }^{\prime \prime}\right)$ for both compounds $\mathbf{H}_{2} \mathbf{S Q}-\mathbf{Y b}$ and Q-Yb were measured using immobilized selected and crunched single crystals. For both compounds, any out-of-phase signal was not detected in zero magnetic field in the 1-10000 Hz frequency range. Such absence of out-of-phase component of the ac susceptibility in 0 Oe is common for the $\mathrm{Yb}^{\mathrm{III}}$-based coordination complexes because of the fast magnetic relaxation due to efficient Quantum Tunneling of the Magnetization (QTM) which can be cancelled by applying an external magnetic field [45]. Thus the field dependence of the magnetic susceptibility is studied in detail (Figure 4 and Figure S2). For both compounds, the application of a small magnetic field led to the appearance of out-of-phase component of the magnetic susceptibility and the optimal value of the applied magnetic field was chosen thank to the field dependence of the relaxation time (Figure S3). The scan field revealed an unusual behavior since applying a small magnetic field led to the slowest magnetic relaxation of a fraction of the sample (about $50 \%$ ) while increasing the value of the applied magnetic field accelerates the magnetic relaxation but increases the relaxing fraction. In fact applying a magnetic field tends to cancel the QTM (appearance of the slow magnetic relaxation fraction) but favor the appearance of field dependent under energy barrier mechanism (direct process). Thus a good compromised magnetic field value could be 800 Oe for $\mathbf{H}_{2} \mathbf{S Q}-\mathbf{Y b}$ while for such field value the maximum was observed at the highest accessible frequency range for $\mathbf{Q}-\mathbf{Y} \mathbf{b}$ at $2 \mathrm{~K}$ (Figure 4 and Figure S2). 


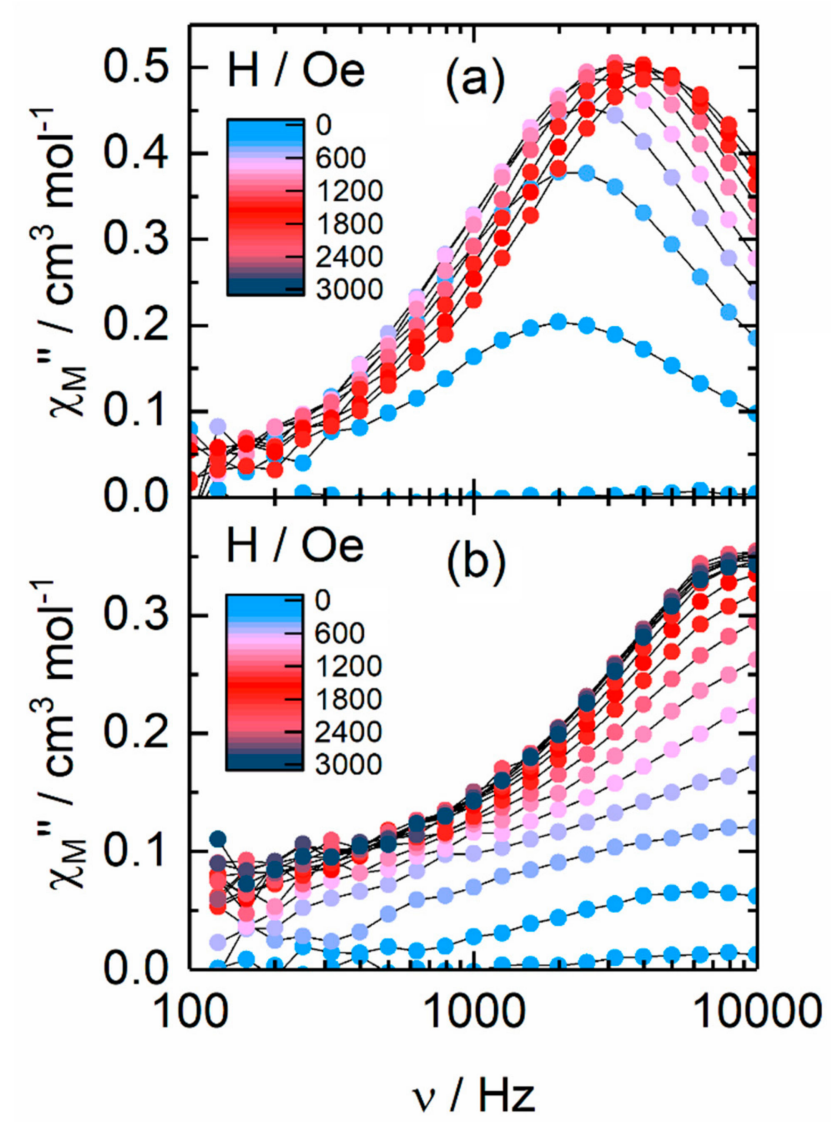

Figure 4. Frequency dependence of $\chi_{\mathrm{M}}$ " between 0 and 3000 Oe for $\mathbf{H}_{2} \mathbf{S Q}-\mathbf{Y b}(\mathbf{a})$ and $\mathbf{Q}-\mathbf{Y b}(\mathbf{b})$ at $2 \mathrm{~K}$.

At this point one can notice that the oxidation of the $\mathbf{H}_{2} \mathrm{SQ}$ ligand is accompanied by a fastening of the magnetic relaxation by a factor 5 at $2 \mathrm{~K}$.

Under an applied field of $\mathrm{H}=800 \mathrm{Oe}, \mathbf{H}_{2} \mathbf{S Q}-\mathbf{Y b}$ highlighted a frequency dependence of the out-of-phase signal of the magnetization (Figure 5a and Figure S4) which can be analyzed in the framework of the extended Debye model [46-48]. The temperature dependence of the relaxation time is extracted (see Supplementary Information for details) and depicted in Figure 5b (Table S3) and the normalized Argand (Figure S5) concluded that at such magnetic field more than $90 \%$ of the sample was slowly relaxing. The relaxation time follows two thermally dependent Orbach and direct processes of relaxation:

$$
\tau^{-1}=\tau_{0}^{-1} \exp (\Delta / \mathrm{T})+\mathrm{BTH}^{\mathrm{m}}
$$

The best fit was obtained using the Equation (1) with $\tau_{0}=9.25(50) \times 10^{-8} \mathrm{~s}$ and $\Delta=10.0(2) \mathrm{K}$, and $\mathrm{B}=1.23(4) \times 10^{-8} \mathrm{~s}^{-1} \mathrm{~K}^{-1} \mathrm{Oe}^{-4}$ and $\mathrm{m}=4$ (fixed) where $\Delta$ is the energy barrier, $\mathrm{B}$ and $\mathrm{m}$ are constant parameters for the direct relaxation process (Figure $5 b$ ). The involvement of direct process is strongly supported by the field dependence of the relaxation time (Figures S2 and S3) and the selected 800 Oe applied magnetic field. All the other attempts to include other magnetic relaxation processes led to a predominant Raman mechanism which exclude both remaining QTM and Direct process (Figures S6-S8). Nevertheless, the field dependence of the magnetic susceptibility (Figures S2-S3) imposed the presence of the Direct process. 

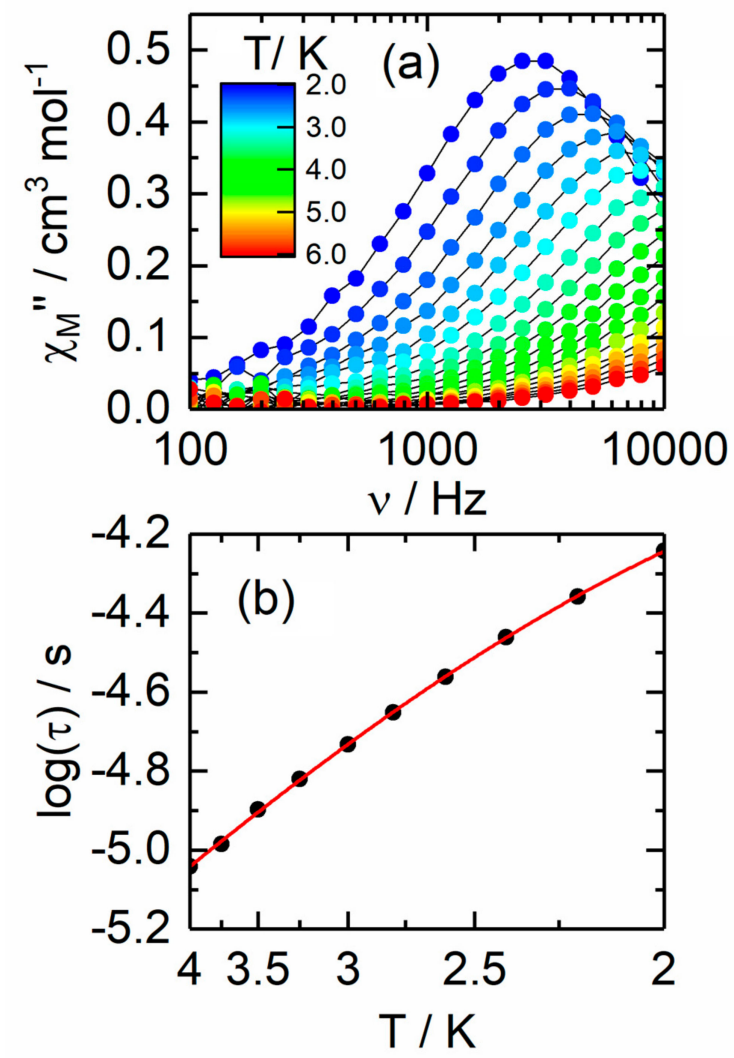

Figure 5. (a) Frequency dependence of $\chi_{M}$ " between 2 and $6 \mathrm{~K}$ for $\mathbf{H}_{2} \mathbf{S Q}-\mathbf{Y b}$ at $800 \mathrm{Oe}$, (b) Temperature variation of the relaxation time for $\mathbf{H}_{2} \mathbf{S Q}-\mathbf{Y b}$ in the temperature range of 2-4 K with the best fitted curve with the Arrhenius law (red line).

\subsubsection{Photophysical Properties}

The UV-visible absorption properties for $\mathbf{H}_{2} \mathbf{S Q} \mathbf{Q} \mathbf{Y b}$ and Q-Yb have been studied in a $\mathrm{CH}_{2} \mathrm{Cl}_{2}$ solution (Figure 6a). The spectra are dominated by the $\pi-\pi^{*} h f a c^{-}$transition at high energy $\left(33000 \mathrm{~cm}^{-1}\right)$ and Intra-Ligand Charge Transfers (ILCTs) at low energy. $\mathrm{S} \rightarrow \mathrm{L}$ and $\mathrm{H} \rightarrow \mathrm{L}$ (where $\mathrm{S}=$ Single Occupied Molecular Orbital, L = Lowest Unoccupied Molecular Orbital and H = Highest Occupied Molecular Orbital) ILCT have been previously identified for the corresponding free $\mathbf{H}_{2} \mathbf{S Q}$ and $\mathbf{Q}$ triads with the $\mathrm{S}$ and $\mathrm{H}$ mainly localized on the extended TTF while $\mathrm{L}$ is situated on the semiquinone and quinone acceptors [36,49,50]. Thus for $\mathbf{H}_{\mathbf{2}} \mathbf{S Q} \mathbf{Q} \mathbf{Y b}$ and based on DFT calculations for the free $\mathbf{H}_{\mathbf{2}} \mathbf{S Q t r i a d}$ [36], the strong absorption band centered at $12500 \mathrm{~cm}^{-1}$ is attributed to the $\mathrm{H} \rightarrow$ L ILCT and the shoulder centered at $20.000 \mathrm{~cm}^{-1}$ is attributed to $\mathrm{S} \rightarrow$ L ILCT. For $\mathbf{Q}-\mathbf{Y b}$, the most intense absorption band at $9800 \mathrm{~cm}^{-1}$ is attributed to the $\mathrm{H} \rightarrow$ L ILCT. The oxidation of the $\mathbf{H}_{2} \mathbf{S Q} \mathbf{Y} \mathbf{Y b}$ into Q-Yb induced a redshift of the $\mathrm{H} \rightarrow \mathrm{L}$ ILCT from $12500 \mathrm{~cm}^{-1}$ to $9800 \mathrm{~cm}^{-1}$ (average energy value of the maxima). It was previously demonstrated that the low-energy ILCT could be an efficient donating source for sensitization of NIR lanthanide emitters [27,51,52]. Irradiation at $16670 \mathrm{~cm}^{-1}$ (or lower energy) induced the expected ${ }^{2} \mathrm{~F}_{5 / 2} \rightarrow{ }^{2} \mathrm{~F}_{7 / 2} \mathrm{Yb}^{\mathrm{III}}$ emission (Figure $6 \mathrm{~b}$ ) for $\mathbf{H}_{2} \mathbf{S Q} \mathbf{S} \mathbf{Y b}$ whereas after the two-electron oxidation the same irradiation highlighted the total quenching of the NIR emission for $\mathbf{Q}-\mathbf{Y b}$. The NIR luminescence of $\mathbf{H}_{2} \mathbf{S Q} \mathbf{Y b}$ is composed of four components as expected from the splitting of the ${ }^{2} \mathrm{~F}_{7 / 2}$ ground state by the ligand field effect [53-55] localized at $10157 \mathrm{~cm}^{-1}, 9926 \mathrm{~cm}^{-1}, 9639 \mathrm{~cm}^{-1}$ and $9560 \mathrm{~cm}^{-1}$ (Figure $6 \mathrm{~b}$ ). Since the emission of the lanthanide ions can be interpreted as a photography of the ground state energy splitting, the experimental energy barrier determined from the energy gap between the ground and the first excited states is $231 \mathrm{~cm}^{-1}(332 \mathrm{~K})$ which is much more higher than the value determined from the magnetic properties $(10 \mathrm{~K})$. Such observation may signify that the Orbach contribution is negligible and the magnetic relaxation occurs mainly through the direct process. 

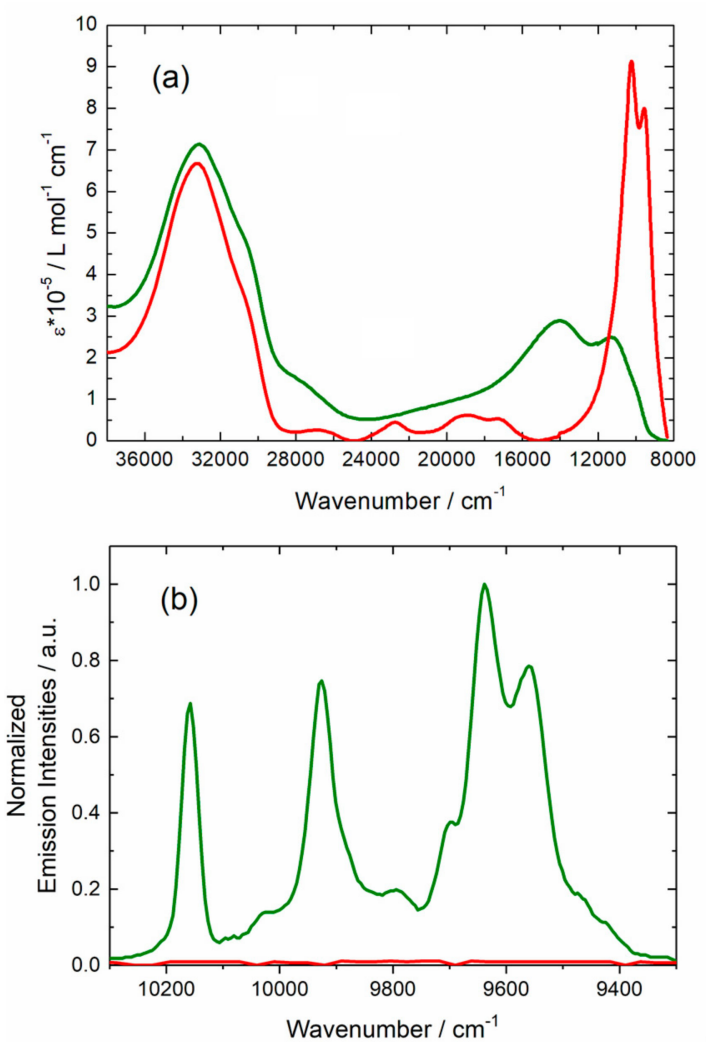

Figure 6. (a) Experimental UV-visible absorption spectra at room temperature of $\mathbf{H}_{\mathbf{2}} \mathbf{S Q} \mathbf{Y} \mathbf{Y b}$ (green line) and Q- $\mathbf{~} \mathbf{b}$ (red line) in $\mathrm{CH}_{2} \mathrm{Cl}_{2}$ solution $\left(\mathrm{C}=4 \times 10^{-5} \mathrm{~mol} \cdot \mathrm{L}^{-1}\right)$. (b) Emission spectra at $77 \mathrm{~K}$ of $\mathbf{H}_{2} \mathbf{S Q} \mathbf{Y b}$ (green line) and Q-Yb (red line) for an irradiation energy of $16670 \mathrm{~cm}^{-1}$ in solid-state.

The efficiency of the NIR emission sensitization strongly depends on the energy position of the ILCT. The donating ILCT ( $\mathrm{S} \rightarrow \mathrm{L}$ in Scheme 2) in $\mathbf{H}_{\mathbf{2}} \mathbf{S Q} \mathbf{S} \mathbf{Y b}$ is localized $2300 \mathrm{~cm}^{-1}$ above the emitting ${ }^{2} \mathrm{~F}_{5 / 2}$ level which is well suited for an efficient sensitization while both donating and emitting levels are localized at the same energy in Q-Yb leading to efficient back energy transfer (BET) and thus a quenching of the NIR emission.

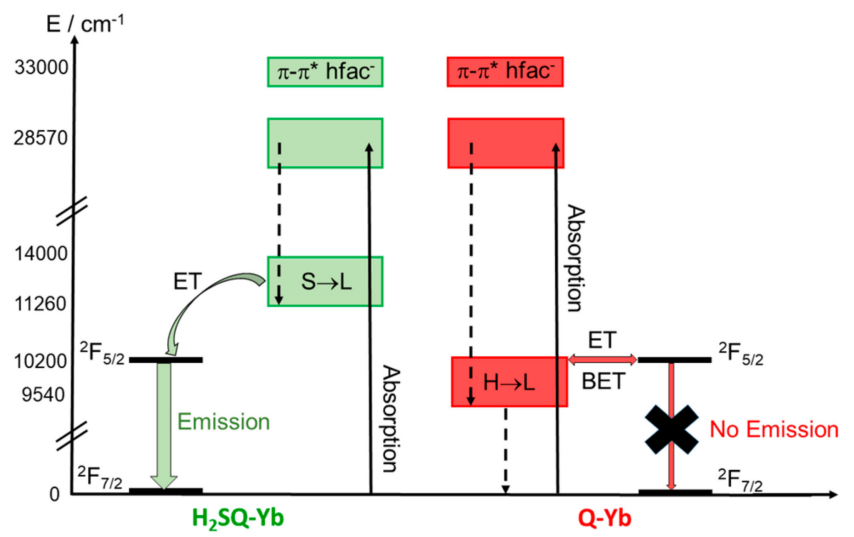

Scheme 2. Proposed sensitization process in $\mathbf{H}_{2} \mathbf{S Q}-\mathbf{Y b}$ (left part) and $\mathbf{Q}-\mathbf{Y b}$ (right part). Dashed lines represent the non-radiative deactivations, ET = Energy Transfer, BET = Back Energy Transfer, $\mathrm{H}=\mathrm{HOMO}, \mathrm{L}=\mathrm{LUMO}$ and $\mathrm{S}=\mathrm{SOMO}$. 


\section{Materials and Methods}

\subsection{Synthesis. General Procedures and Materials}

The precursor Dy(hfac) $)_{3} \cdot 2 \mathrm{H}_{2} \mathrm{O}$ ( $\mathrm{hfac}^{-}=1,1,1,5,5,5$-hexafluoroacetonate anion) and the 2,2'benzene-1,4-diylbis(6-hydroxy-4,7-di-tert-butyl-1,3-benzodithiol-2-ylium-5-olate ligand $\left(\mathbf{H}_{2} \mathbf{S Q}\right)$ were synthesized following previously reported methods [36,56]. All other reagents were commercially available and used without further purification.

\subsection{Synthesis of complexes $\left[Y b_{2}(h f a c)_{6}\left(\mathrm{H}_{2} \mathrm{SQ}\right)\right] \cdot 0.5 \mathrm{CH}_{2} \mathrm{Cl}_{2}\left(\mathrm{H}_{2} \mathrm{SQ}-\mathrm{Yb}\right)$ and $\left[Y b_{2}(h f a c)_{6}(Q)\right](Q-Y b)$}

$\left[\mathrm{Yb}_{2}(\mathrm{hfac})_{6}\left(\mathrm{H}_{2} \mathrm{SQ}\right)\right] \cdot 0.5 \mathrm{CH}_{2} \mathrm{Cl}_{2}\left(\mathrm{H}_{2} \mathrm{SQ}-\mathbf{Y b}\right) .66 .4 \mathrm{mg}$ of $\mathrm{Yb}(\mathrm{hfac})_{3} \cdot 2 \mathrm{H}_{2} \mathrm{O}(0.08 \mathrm{mmol})$ were dissolved in $10 \mathrm{~mL}$ of $\mathrm{CH}_{2} \mathrm{Cl}_{2}$ and then added to a purple solution of $10 \mathrm{~mL}$ of $\mathrm{CH}_{2} \mathrm{Cl}_{2}$ containing $26.4 \mathrm{mg}$ of $\mathbf{H}_{2} \mathrm{SQ}$ (0.04 mmol). The purple solution of $\mathbf{H}_{2} \mathrm{SQ}$ immediately turned blue with the addition of the $\mathrm{Yb}^{\mathrm{III}}$ salt. After 15 minutes of stirring, $20 \mathrm{~mL}$ of $n$-hexane were layered at room temperature in the dark. Slow diffusion leads to dark blue single crystals of $\mathbf{H}_{2} \mathbf{S Q}-\mathbf{Y b}$ which are suitable for X-ray studies. Yield (determined from isolated single crystals) $40.4 \mathrm{mg}$ (44\%). Anal. Calcd (\%) for $\mathrm{C}_{66.5} \mathrm{H}_{49} \mathrm{Yb}_{2} \mathrm{~F}_{36} \mathrm{O}_{16} \mathrm{~S}_{4} \mathrm{Cl}_{\text {: }}$ C 37.73, H 2.13; found: C 38.09, H 2.22.

$\left[Y b_{2}(h f a c)_{6}(Q)\right](Q-Y b) .13 .2 \mathrm{mg}$ of $\mathbf{H}_{2} \mathbf{S Q}(0.02 \mathrm{mmol})$ were dissolved in $20 \mathrm{~mL}$ of $\mathrm{CH}_{2} \mathrm{Cl}_{2}$ and then stirred in presence of $1.5 \mathrm{~g}$ of $\mathrm{MnO}_{2}$. The starting purple solution turned green (oxidation of $\mathrm{H}_{2} \mathrm{SQ}$ into Q) and after 45 min of stirring it was filtered directly in a $\mathrm{CH}_{2} \mathrm{Cl}_{2}$ solution $(5 \mathrm{~mL})$ of $\mathrm{Yb}(\mathrm{hfac})_{3} \cdot 2 \mathrm{H}_{2} \mathrm{O}$ $(33.2 \mathrm{mg}, 0.04 \mathrm{mmol})$. The green solution turned to a dark pink color. Addition of $n$-pentane into the resulting dark pink solution led to formation of a dark pink crystalline powder. Yield $32.0 \mathrm{mg}$ (71 \%). Anal. Calcd (\%) for $\mathrm{C}_{66} \mathrm{H}_{46} \mathrm{Yb}_{2} \mathrm{~F}_{36} \mathrm{O}_{16} \mathrm{~S}_{4}$ : C 35.18, H 2.04; found: C 35.66, H 2.19.

\subsection{Crystallography}

Single crystal of $\mathbf{H}_{2} \mathbf{S Q}-\mathbf{Y b}$ was mounted on a APEXIII D8 VENTURE AXS diffractometer for data collection (Bruker, Billerica, MA, USA), $\mathrm{MoK}_{\alpha}$ radiation source, $\lambda=0.71073 \AA$ A), from the Centre de Diffractométrie (CDIFX), Université de Rennes 1, France (Table S1). Structure was solved with a direct method using the SHELXT program [57] and refined with a full matrix least-squares method on $\mathrm{F}^{2}$ using the SHELXL-14/7 program [58]. Complete crystal structure results as a CIF file including bond lengths, angles, and atomic coordinates are deposited as Supporting Information. CCDC number is 1970010 for compound $\mathbf{H}_{\mathbf{2}} \mathbf{S Q} \mathbf{Q} \mathbf{Y b}$.

\subsection{Physical Measurements}

The elemental analyses of the compounds were performed at the Centre Régional de Mesures Physiques de l'Ouest, Rennes, France. Absorption spectra were recorded on a V-650 spectrophotometer (JASCO, Easton, MD, USA) in dilute solutions, using spectrophotometric grade solvents. Emission spectra were measured using Fluorolog-3 fluorimeter (Horiba-Jobin-Yvon, Kyoto, Japan). The steady-state luminescence was excited by unpolarized light from a $450 \mathrm{~W}$ xenon continuous wave (CW) lamp and detected at an angle of $90^{\circ}$ by a nitrogen-cooled InGAs detector (Horiba-Jobin-Yvon, Kyoto, Japan). Quartz tubes containing solid samples of each compound were place in a quartz dewar containing liquid nitrogen The dc magnetic susceptibility measurements were performed on solid polycrystalline samples with a MPMS-XL SQUID magnetometer (Quantum Design Inc., San Diego, CA, USA) between 20 and $300 \mathrm{~K}$ in applied magnetic field of $2 \mathrm{kOe}$ between 2 and $20 \mathrm{~K}$ and $10 \mathrm{kOe}$ above. The microcrystallites are immobilized in a pellet made with Teflon tape. These measurements were all corrected for the diamagnetic contribution as calculated with Pascal's constants. The ac magnetic susceptibility measurements were performed on a Quantum Design PPMS (Quantum Design Inc., San Diego, CA, USA) system equipped with ac/dc probe.

\subsection{Computational Details}

The structure optimization of $\mathbf{Q}-\mathbf{Y b}$ was carried out at the Kohn-Sham density functional theory (DFT) level with the Amsterdam Density Functional (ADF) [59-61] software package. In this calculation, 
the $\mathrm{Yb}^{3+}$ center was replaced by the closed-shell $\mathrm{Lu}^{3+}$ ion, and the scalar all-electron zeroth-order regular approximation (ZORA) [62] was employed for the treatment of the scalar relativistic effects. The PBE functional (Perdew-Burke-Ernzerhof) [63] from the generalized gradient approximation, was used along with the triple- $\zeta$ polarized Slater0type orbital (STO) all-electron basis set with one set of polarization function for all atoms (TZP) [64].

\section{Conclusions}

In this article, the 2,2'-benzene-1,4-diylbis(6-hydroxy-4,7-di-tert-butyl-1,3-benzodithiol-2-ylium5-olate triad $\left(\mathbf{H}_{2} \mathbf{S Q}\right)$ allowed the formation of a dinuclear complex of formula [ $\mathrm{Yb}_{2}(\mathrm{hfac})_{6}\left(\mathbf{H}_{2} \mathbf{S Q}\right)$ ] $.0 .5 \mathrm{CH}_{2} \mathrm{Cl}_{2}\left(\mathrm{H}_{2} \mathrm{SQ}-\mathbf{Y b}\right)$ in which the two $\mathrm{Yb}^{\mathrm{III}}$ ions are coordinated to the bischelating protonated semiquinone units. After the chemical oxidation of the $\mathbf{H}_{2} \mathbf{S Q}$ triad, the resulting 2,2'-cyclohexa2,5-diene-1,4-diylidenebis(4,7-di-tert-butyl-1,3-benzodithiole-5,6-dione $\mathbf{Q}$ triad allowed the formation of a new dinuclear complex $\left[\mathrm{Yb}_{2}(\mathrm{hfac})_{6}(\mathbf{Q})\right](\mathbf{Q}-\mathbf{Y b})$. The two-electron oxidation of the triad induced changes in the electronic absorption spectra with a red shift of the ILCT bands. For $\mathbf{H}_{\mathbf{2}} \mathbf{S Q} \mathbf{S} \mathbf{Y}$, irradiation of the ILCT induced an efficient sensitization of the $\mathrm{Yb}$ III NIR emission while the lower-energy ILCT for $\mathbf{Q}-\mathbf{Y b}$ allowed back energy transfer and so a quenching of the NIR emission. Both compounds behave as field-induced SMM with a fastening of the magnetic relaxation after oxidation. In conclusion the oxidation of the $\mathbf{H}_{2} \mathrm{SQ}$ triad into the $\mathbf{Q}$ one induced a dual magnetic modulation and luminescence quenching.

Supplementary Materials: The following are available online at http://www.mdpi.com/1420-3049/25/3/492/s1, Figure S1. ORTEP view of the asymmetric unit in $\left[\mathrm{Yb}_{2}(\mathrm{hfac})_{6}\left(\mathrm{H}_{2} \mathrm{SQ}\right)\right] \cdot 0.5 \mathrm{CH}_{2} \mathrm{Cl}_{2}\left(\mathbf{H}_{2} \mathbf{S Q} \mathbf{Y} \mathbf{Y b}\right)$. Thermal ellipsoids are drawn at $30 \%$ probability. Hydrogen atoms and $\mathrm{CH}_{2} \mathrm{Cl}_{2}$ molecule of crystallization are omitted for clarity. Figure S2. Scan field of the frequency dependence of the in phase $\left(\chi_{M}{ }^{\prime}\right)$ component of the ac magnetic susceptibility for $\mathbf{H}_{2} \mathbf{S Q} \mathbf{Y b}(\mathrm{a})$ and $\mathbf{Q}-\mathbf{Y b}(\mathrm{b})$. Figure S3. Field dependence of the magnetic relaxation time of $\mathbf{H}_{2} \mathbf{S Q} \mathbf{Y} \mathbf{Y b}$. Figure S4. Frequency dependence of the in-phase component of the magnetic susceptibility for $\mathbf{H}_{2} \mathbf{S Q}-\mathbf{Y b}$ measured under a DC applied magnetic field of 800 Oe in the 2-6 K temperature range. Figure S5. Normalized Cole-Cole plots for $\mathbf{H}_{2} \mathbf{S Q}-\mathbf{Y b}$ at several temperatures between 2 and $3 \mathrm{~K}$. Table S1: X-ray crystallographic data for $\mathbf{H}_{2} \mathbf{S Q}-\mathbf{Y b}$. Table S2: SHAPE analysis of the coordination polyhedra around the lanthanide in $\mathbf{H}_{\mathbf{2}} \mathbf{S Q} \mathbf{Q} \mathbf{Y} \mathbf{b}$ and $\mathbf{Q}-\mathbf{Y b}$.; Table S3: Best fitted parameters $\left(\chi_{T}, \chi_{S}, \tau\right.$ and $\left.\alpha\right)$ with the extended Debye model for compound $\mathbf{H}_{2} \mathbf{S Q} \mathbf{Y} \mathbf{Y b}$ at 800 Oe in the temperature range $2-4 \mathrm{~K}$.

Author Contributions: V.C. and V.K. performed the organic syntheses; B.L. performed the coordination chemistry and crystallizations; V.D. realized the single crystal X-ray diffraction experiments and structure refinements; O.C. and J.F.G. performed and analyzed the magnetic measurements, F.R. and O.M. performed the photophysical measurements, F.G. and B.L.G. performed the DFT calculations, F.P. conceived and designed the experiments; F.P., O.C., V.K. and B.L.G. contributed to the writing of the article. All authors have read and agreed to the published version of the manuscript.

Funding: This work was supported by Région Bretagne, Rennes Métropole, CNRS, Université de Rennes 1, France-Russia MULTISWITCH PRC Grant (No. 199001), RFBR according to the research project No. 18-53-15004, the Russian state assignment, and the European Commission through the ERC-CoG 725184 MULTIPROSMM (project No. 725184). B.L.G. and F.G. thank the French GENCI/IDRIS-CINES center for high-performance computing resources.

Conflicts of Interest: The authors declare no conflict of interest. The founding sponsors had no role in the design of the study; in the collection, analyses, or interpretation of data; in the writing of the manuscript, and in the decision to publish the results.

\section{References}

1. Sessoli, R.; Gatteschi, D.; Caneschi, A.; Novak, M.A. Magnetic bistability in a metal-ion cluster. Nature 1993, 365, 141-143. [CrossRef]

2. Ishikawa, N.; Sugita, M.; Ishikawa, T.; Koshihara, S.-Y.; Kaizu, Y. Lanthanide Double-Decker Complexes Functioning as Magnets at the Single-Molecular Level. J. Am. Chem. Soc. 2003, 125, 8694-8695. [CrossRef]

3. Mannini, M.; Pineider, F.; Sainctavit, P.; Danieli, C.; Otero, E.; Sciancalepore, C.; Talarico, A.M.; Arrio, M.-A.; Cornia, A.; Gatteschi, D.; et al. Magnetic memory of a single-molecule quantum magnet wired to a gold surface. Nat. Mater. 2009, 8, 194-197. [CrossRef]

4. Affronte, M. Molecular nanomagnets for information technologies. J. Mater. Chem. 2009, 19, 1731-1737. [CrossRef] 
5. Guo, F.-S.; Day, B.-M.; Chen, Y.-C.; Tong, M.-L.; Mansikkamäki, A.; Layfield, R.A. A Dysprosium Metallocene Single-Molecule Magnet Functioning at the Axial Limit. Angew. Chem. Int. Ed. 2017, 56, 11445-11449. [CrossRef] [PubMed]

6. Goodwin, C.A.P.; Ortu, F.; Reta, D.; Chilton, N.F.; Mills, D.P. Molecular magnetic hysteresis at 60 kelvin in dysprosocenium. Nature 2017, 548, 439-442. [CrossRef] [PubMed]

7. McClain, K.R.; Gould, C.A.; Chakarawet, K.; Teat, S.J.; Groshens, T.J.; Long, J.R.; Harvey, B.G. High-temperature magnetic blocking and magneto-structural correlations in a series of dysprosium(III) metallocenium single-molecule magnets. Chem. Sci. 2018, 9, 8492-8503. [CrossRef] [PubMed]

8. Guo, F.-S.; Day, B.-M.; Chen, Y.-C.; Tong, M.-L.; Mansikkamäki, A.; Layfield, R.A. Magnetic hysteresis up to 80 kelvin in a dysprosium metallocene single-molecule magnet. Science 2018, 362, 1400-1403. [CrossRef] [PubMed]

9. Suzuki, K.; Sato, R.; Mizuno, N. Reversible switching of single-molecule magnet behaviors by transformation of dinuclear dysprosium cores in polyoxometalates. Chem. Sci. 2013, 4, 596-600. [CrossRef]

10. Liu, J.-L.; Chen, Y.-C.; Zheng, Y.-Z.; Lin, W.-Q.; Ungur, L.; Wernsdorfer, W.; Chibotaru, L.F.; Tong, M.-L. Switching the anisotropy barrier of a single-ion magnet by symmetry change from quasi- $D_{5 \mathrm{~h}}$ to quasi- $O_{\mathrm{h}}$. Chem. Sci. 2013, 4, 3310-3316.

11. Zhang, X.; Vieru, V.; Feng, X.; Liu, J.-L.; Zhang, Z.; Na, B.; Shi, W.; Wang, B.-W.; Powell, A.K.; Chibotaru, L.F.; et al. Influence of Guest Exchange on the Magnetization Dynamics of Dilanthanide Single-Molecule-Magnet Nodes within a Metal-Organic Framework. Angew. Chem. Int. Ed. 2015, 54, 9861-9865. [CrossRef] [PubMed]

12. Ge, J.-Y.; Cui, L.; Li, J.; Yu, F.; Song, Y.; Zhang, Y.-Q.; Zuo, J.-L.; Kurmoo, M. Modulation Single-Molecule Magnetic Behavior of a Dinuclear Erbium(III) Complex by Solvent Exchange. Inorg. Chem. 2017, 56, 336-343. [CrossRef] [PubMed]

13. Pinkowicz, D.; Ren, M.; Zheng, L.-M.; Sato, S.; Hasegawa, M.; Morimoto, M.; Irie, M.; Breedlove, B.K.; Cosquer, G.; Katoh, K.; et al. Control of the Single-Molecule Magnet Behavior of Lanthanide-Diarylethene Photochromic Assemblies by Irradiation with Light. Chem. Eur. J. 2014, 20, 12502-12513. [CrossRef] [PubMed]

14. Cosquer, G.; Morimoto, M.; Irie, M.; Fetoh, A.; Breedlove, B.K.; Yamashita, M. Photo-control of the magnetic properties of Dy(III) and Ho(III) homometal coordination polymers bridged by a diarylethene ligand. Dalton Trans. 2015, 44, 5996-6002. [CrossRef]

15. Wang, L.-F.; Qiu, J.-Z.; Liu, J.-L.; Chen, Y.-C.; Jia, J.-H.; Jover, J.; Ruiz, E.; Tong, M.-L. Modulation of single-molecule magnet behaviour via photochemical [2+2] cycloaddition. Chem. Commun. 2015, 51, 15358-15361. [CrossRef]

16. Selvanathan, P.; Huang, G.; Guizouarn, T.; Roisnel, T.; Fernandez-Garcia, G.; Totti, F.; Le Guennic, B.; Calvez, G.; Bernot, K.; Norel, L.; et al. Highly Axial Magnetic Anisotropy in a N3O5 Dysprosium(III) Coordination Environment Generated by a Merocyanine Ligand. Chem. Eur. J. 2016, 22, 15222-15226. [CrossRef]

17. Tian, H.; Su, J.-B.; Bao, S.S.; Kurmoo, M.; Huang, X.-D.; Zhang, Y.-Q.; Zheng, L.-M. Reversible ON-OFF switching of single-molecule-magnetism associated with single-crystal-to-single-crystal structural transformation of a decanuclear dysprosium phosphate. Chem. Sci. 2018, 9, 6424-6433. [CrossRef]

18. Liang, Z.; Damjanovic, M.; Kamila, M.; Cosquer, G.; Breedlove, B.K.; Enders, M.; Yamashita, M. Proton Control of the Lanthanoid Single-Ion Magnet Behavior of a Double-Desker Complex with an Indolenine-Substituted Annulene Ligand. Inorg. Chem. 2017, 56, 6512-6521. [CrossRef]

19. Zhang, P.; Perfetti, M.; Kern, M.; Hallmen, P.P.; Ungur, L.; Lenz, S.; Ringenberg, M.R.; Frey, W.; Stoll, H.; Rauhut, G.; et al. Exchange coupling and single molecule magnetism in redox-active tetraoxolene-bridged dilanthanide complexes. Chem. Sci. 2018, 9, 1221-1230. [CrossRef]

20. Dolinar, B.S.; Gomez-Coca, S.; Alexandropoulos, D.I.; Dunbar, K.R. An air stable radical-bridged dysprosium single molecule magnet and its neutral counterpart: Redox switching of magnetic relaxation dynamics. Chem. Commun. 2017, 53, 2283-2286. [CrossRef]

21. Takamatsu, S.; Isikawa, T.; Koshihara, S.Y.; Ishikawa, N. Signifant Increase of the Barrier Energy for Magnetization Reversal of a Single-4f-Ionic Single-Molecule Magnet by a Longitudinal Contraction of the Coordination Space. Inorg. Chem. 2007, 46, 7250-7252. [CrossRef] [PubMed]

22. Norel, L.; Feng, M.; Bernot, K.; Roisnel, T.; Guizouarn, T.; Costuas, K.; Rigaut, S. Redox Modulation of Magnetic Slow Relaxation in a 4f-Based Single-Molecule Magnet with a 4d Carbon-Rich Ligand. Inorg. Chem. 2014, 53, 2361-2363. [CrossRef] [PubMed] 
23. Dickie, C.M.; Laughlin, A.L.; Wofford, J.D.; Bhuvanesh, N.S.; Nippe, M. Transition metal redox switches for reversible "on/off" and "slow/fast" single-molecule magnet behaviour in dysprosium and erbium bis-diamidoferrocene complexes. Chem. Sci. 2017, 8, 8039-8049. [CrossRef] [PubMed]

24. Cador, O.; Le Guennic, B.; Pointillart, F. Electro-Activity and Magnetic Switching in Lanthanide-Based Single-Molecule Magnets. Inorg. Chem. Front. 2019, 6, 3398-3417. [CrossRef]

25. Sy, M.; Nonat, A.; Hildebrandt, N.; Charbonnière, L.J. Lanthanide-based luminescence biolabelling. Chem. Commun. 2016, 52, 5080-5095. [CrossRef]

26. Zhang, K.Y.; Yu, Q.; Wei, H.; Liu, S.; Zhao, Q.; Huang, W. Long-Lived Emission Probes for time-Resolved Photoluminescence Bioimaging and Biosensing. Chem. Rev. 2018, 118, 1770-1839. [CrossRef]

27. D'Aléo, A.; Pointillart, F.; Ouahab, L.; Andraud, C.; Maury, O. Charge transfer excited states sensitization of lanthanide emitting from the visible to the near-infra-red. Coord. Chem. Rev. 2012, 256, 1604-1620. [CrossRef]

28. Pointillart, F.; Le Guennic, B.; Cador, O.; Maury, O.; Ouahab, L. Lanthanide Ion and Tetrathiafulvalene-Based Ligand as a "Magic" Couple toward Luminescence, Single Molecule Magnets, and Magnetostructural Correlations. Acc. Chem. Res. 2015, 48, 2834-2842. [CrossRef]

29. Bünzli, J.-C.G.; Piguet, C. Taking advantage of luminescent lanthanide ions. Coord. Chem. Rev. 2005, 34, 1048-1077. [CrossRef]

30. Eliseeva, S.V.; Bünzli, J.-C.G. Lanthanide luminescence for functional materials and bio-sciences. Chem. Soc. Rev. 2010, 39, 189-227. [CrossRef]

31. Bünzli, J.-C.G. On the design of highly luminescent lanthanide complexes. Coord. Chem. Rev. 2015, 293-294, 19-47. [CrossRef]

32. Di Piazza, E.; Norel, L.; Costuas, K.; Bourdolle, A.; Maury, O.; Rigaut, S. D-f Heterobimetallic Association between Ytterbium and Ruthenium Carbon-Rich Complexes: Redox Commutation of Near-IR Luminescence. J. Am. Chem. Soc. 2011, 133, 6174-6176. [CrossRef] [PubMed]

33. Al Sabea, H.; Norel, L.; Galangau, O.; Hijazi, H.; Métivier, R.; Roisnel, T.; Maury, O.; Bucher, C.; Riobé, F.; Rigaut, S. Dual Light and Redox Control of NIR Luminescence with Complementary Photochromic and Organometallic Antennae. J. Am. Chem. Soc. 2019. [CrossRef] [PubMed]

34. Tropiano, M.; Kilah, N.L.; Morten, M.; Rahman, H.; Davis, J.J.; Beer, P.D.; Faulkner, S. Reversible Luminescence Switching of a Redox-Active Ferrocene-Europium Dyad. J. Am. Chem. Soc. 2011, 133, 11847-11849. [CrossRef] [PubMed]

35. Molloy, J.K.; Jarjayes, O.; Philouze, C.; Fedele, L.; Imbert, D.; Thomas, F. A redox active switch for lanthanide luminescence in phenolate complexes. Chem. Commun. 2017, 53, 605-608. [CrossRef]

36. Chalkov, N.O.; Cherkasov, V.K.; Abakumov, G.A.; Romanenko, G.V.; Ketkov, S.Y.; Smolyaninov, I.V.; Starikov, A.G.; Kuropatov, V.A. Compactly Fused o-Quinone-Extended Tetrathiafulvalene-o-Quinone Triad-A Redox-Amphoteric Ligand. Eur. J. Org. Chem. 2014, 4571-4576. [CrossRef]

37. Flores Gonzalez, J.; Cador, O.; Ouahab, L.; Norkov, S.; Kuropatov, V.; Pointillart, F. Field-Induced Dysprosium Single-Molecule Magnet Involving a Fused o-Semiquinone-Extended-Tetrathiafulvalene-o-Semiquinone Bridging Triad. Inorganics 2018, 6, 45. [CrossRef]

38. Jones, A.E.; Christensen, C.A.; Perepichka, D.F.; Batsanov, A.S.; Beeby, A.; Low, P.J.; Bryce, M.R.; Parker, A.W. Photochemistry of the $\pi$-Extended 9,10-Bis(1,3-dithiol-2-ylidene)-9,10-dihydroanthracene System: Generation and Characterisation of the Radical Cation, Dication, and Derived Products. Chem. Eur. J. 2001, 7, 973-978. [CrossRef]

39. Cooper, W.F.; Edmonds, J.W.; Wudl, F.; Coppens, P. The 2-2'-bi-1,3-dithiole. Cryst. Struct. Commun. 1974, 3, 23-26.

40. Ellern, A.; Bernstein, J.; Becker, J.Y.; Zamir, S.; Shahal, L.; Cohen, S. New Polymorphic Modification of tetrathiafulvalene. Crystal Structure, Lattice Energy and Intermolecular Interactions. Chem. Mater. 1994, 6, 1378-1385. [CrossRef]

41. Llunell, M.; Casanova, D.; Cirera, J.; Bofill, J.M.; Alemany, P.; Alvarez, S. SHAPE, Version 2.1.; Universitat de Barcelona: Barcelona, Spain, 2013.

42. Pointillart, F.; Kuropatov, V.; Mitin, A.; Maury, O.; Le Gal, Y.; Golhen, S.; Cador, O.; Cherkasov, V.; Ouahab, L. Lanthanide-Based Dinuclear Complexes Involving an o-Quinone-Tetrathiafulvalene-o-Quinone Bridging Ligand: X-ray Structures, Magnetic and Photophysical Properties. Eur. J. Inorg. Chem. 2012, 4708-4718. [CrossRef]

43. Pointillart, F.; Cador, O.; Le Guennic, B.; Ouahab, L. Uncommon lanthanide ions in purely 4 f Single Molecule Magnets. Coord. Chem. Rev. 2017, 346, 150-175. [CrossRef] 
44. Kahn, O. Molecular Magnetism; VCH: Weinhem, Germany, 1993.

45. Poneti, G.; Bernot, K.; Bogani, L.; Caneschi, A.; Sessoli, R.; Wernsdorfer, W.; Gatteschi, D. A rational approach to the modulation of the dynamics of the magnetisation in a dysprosium-nitronyl-nitroxide radical complex. Chem. Commun. 2007, 1807-1809. [CrossRef] [PubMed]

46. Cole, K.S.; Cole, R.H. Dispersion and absorption in dielectrics I. Alternating current characteristics. J. Chem. Phys. 1941, 9, 341-351. [CrossRef]

47. Orbach, R. Spin-lattice relaxation in rare-earth salts. Proc. R. Soc. Lond. A Math. Phys. Eng. Sci. 1961, 264, 458-484.

48. Orbach, R. On the theory of spin-lattice relaxation in paramagnetic salts. Proc. Phys. Soc. 1961, 77, 821-826. [CrossRef]

49. Chalkov, N.O.; Cherkasov, V.K.; Abakumov, G.A.; Starikov, A.G.; Kuropatov, V.A. Protonated paramagnetic redox forms of di-o-quinone bridged with $p$-phenylene-extended TTF: A EPR spectroscopy study. Beilstein J. Org. Chem. 2016, 12, 2450-2456. [CrossRef]

50. Chalkov, N.O.; Cherkasov, V.K.; Abakumov, G.A.; Starikov, A.G.; Kuropatov, V.A. EPR spectroscopy study of di-o-quinone bridged by $\pi$-extended TTF: Redox behavior and binding modes as a ligand. New J. Chem. 2016, 40, 1244-1249. [CrossRef]

51. Ziessel, R.; Ulrich, G.; Charbonnière, L.; Imbert, D.; Scopelliti, R.; Bünzli, J.-C.G. NIR Lanthanide Luminescence by Energy Transfer from Appended Terpyridine-Boradiazaindacene Dyes. Chem. Eur. J. 2006, 12, 5060-5067. [CrossRef]

52. Pointillart, F.; Cauchy, T.; Maury, O.; Le Gal, Y.; Golhen, S.; Cador, O.; Ouahab, L. Tetrathiafulvaleneamido-2-pyridine-N-oxide as Efficient Charge-Transfer Antenna Ligand for the Sensitization of $\mathrm{Yb}^{\mathrm{III}}$ Luminescence in a Series of Lanthanide Paramagnetic Coordination Complexes. Eur. J. Chem. 2010, 16, 11926-11941. [CrossRef]

53. Bünzli, J.-C.G. Benefiting from the Unique Properties of Lanthanide Ions. Acc. Chem. Res. 2006, 39, 53-61. [CrossRef] [PubMed]

54. Eliseeva, S.V.; Bünzli, J.-C.G. Rare earths: Jewels for functional materials of the future. New. J. Chem. 2011, 35, 1165-1176. [CrossRef]

55. Rinehart, J.D.; Long, J.R. Exploiting single-ion anisotropy in the design of f-element single-molecule magnets. Chem. Sci. 2011, 2, 2078-2085. [CrossRef]

56. Richardson, M.F.; Wagner, W.F.; Sands, D.E. Rare-earth trishexafluoroacetylacetonates and related compounds. J. Inorg. Nucl. Chem. 1968, 30, 1275-1289. [CrossRef]

57. Sheldrick, G.L. SHELXT-Integrated space-group and crystal-structure determination. Acta Crystallogr. Sect. A 2015, 71, 3-8. [CrossRef]

58. Sheldrick, G.M. Crystal structure refinement with SHELXL. Acta Crystallogr. Sect. C 2015, 71, 3-8. [CrossRef]

59. Te Velde, G.; Bickelhaupt, F.M.; Baerends, E.J.; van Gisbergen, S.J.A.; Fonseca Guerra, C.; Snijders, J.G.; Ziegler, T. Chemistry with ADF. J. Comput. Chem. 2001, 22, 931-967. [CrossRef]

60. Fonseca Guerra, C.; Snijders, J.G.; te Velde, G.; Baerends, E.J. Towards an order-N DFT method. Theor. Chem. Acc. 1998, 99, 391-403. [CrossRef]

61. Baerends, E.J.; Ziegler, T.; Atkins, A.J.; Autschbach, J.; Bashford, D.; Baseggio, O.; Bérces, A.; Bickelhaupt, F.M.; Bo, C.; Boerritger, P.M.; et al. ADF2017, SCM, Theoretical Chemistry; Vrije Universiteit: Amsterdam, The Netherlands, 2017.

62. Van Lenthe, E.; Baerends, E.J.; Snijders, J.G. Relativistic Regular two-component Hamiltonians. J. Chem. Phys. 1993, 99, 4597-4610. [CrossRef]

63. Perdew, J.P.; Burke, K.; Ernzerhof, M. Generalized Gradient Approximation Made Simple. Phys. Rev. Lett. 1996, 77, 3865-3868. [CrossRef]

64. Van Lenthe, E.; Baerends, E.J. Optimized Slater-type basis sets for the elements 1-118. J. Comput. Chem. 2003, 24, 1142-1156. [CrossRef] [PubMed]

(C) 2020 by the authors. Licensee MDPI, Basel, Switzerland. This article is an open access article distributed under the terms and conditions of the Creative Commons Attribution (CC BY) license (http://creativecommons.org/licenses/by/4.0/). 